\title{
Molecularly Imprinted Polymer Materials as Selective Recognition Sorbents for Explosives: A Review
}

\author{
Mashaalah Zarejousheghani ${ }^{1, *} \mathbb{0}$, Wilhelm Lorenz ${ }^{2}$, Paula Vanninen ${ }^{3}$, Taher Alizadeh ${ }^{4}$, \\ Malcolm Cämmerer ${ }^{1}$ and Helko Borsdorf ${ }^{1}$ (D) \\ 1 UFZ-Helmholtz Centre for Environmental Research, Department Monitoring and Exploration Technologies, \\ Permoserstraße 15, D-04318 Leipzig, Germany; malcolm.caemmerer@ufz.de (M.C.); \\ helko.borsdorf@ufz.de (H.B.) \\ 2 Institute of Chemistry, Food Chemistry and Environmental Chemistry, \\ Martin-Luther-University Halle-Wittenberg, D-06120 Halle, Germany; wilhelm.lorenz@chemie.uni-halle.de \\ 3 VERIFIN, Finnish Institute for Verification of The Chemical Weapons Convention, Department of Chemistry, \\ University of Helsinki, FI-00014 Helsinki Finland; paula.vanninen@helsinki.fi \\ 4 Department of Analytical Chemistry, Faculty of Chemistry, University College of Science, \\ University of Tehran, 1417466191 Tehran, Iran; talizadeh@ut.ac.ir \\ * Correspondence: mashaalah.zare@ufz.de; Tel.: +49-341-235-1455
}

Received: 27 March 2019; Accepted: 10 May 2019; Published: 15 May 2019

check for updates

\begin{abstract}
Explosives are of significant interest to homeland security departments and forensic investigations. Fast, sensitive and selective detection of these chemicals is of great concern for security purposes as well as for triage and decontamination in contaminated areas. To this end, selective sorbents with fast binding kinetics and high binding capacity, either in combination with a sensor transducer or a sampling/sample-preparation method, are required. Molecularly imprinted polymers (MIPs) show promise as cost-effective and rugged artificial selective sorbents, which have a wide variety of applications. This manuscript reviews the innovative strategies developed in 57 manuscripts (published from 2006 to 2019) to use MIP materials for explosives. To the best of our knowledge, there are currently no commercially available MIP-modified sensors or sample preparation methods for explosives in the market. We believe that this review provides information to give insight into the future prospects and potential commercialization of such materials. We warn the readers of the hazards of working with explosives.
\end{abstract}

Keywords: molecularly imprinted polymer; explosive; explosive marker; nitroaromatic compounds; trinitrotoluene; TNT; dinitrotoluene; trinitrophenol; sensors; sample preparation

\section{Introduction}

Molecularly imprinted polymer (MIP) materials are highly cross-linked organic/inorganic co-polymers in which cavities (recognition sites) are imprinted for template molecules, whether explosive molecules or their nonexplosive structural-analogs, as dummy templates. The fundamental principles of MIP-technology can be found in other reviews [1-5]. The advantageous qualities of MIP materials (e.g., low cost, ease of engineering, simplicity of production, potential reusability, physical/chemical stability and their applicability for a wide range of targets) make their applications remarkably widespread [6-12]. MIPs have been used for the selective enrichment of explosives and explosive markers and, as shown in Table 1, nitroaromatic compounds (NACs) are the most important class of chemicals used in these studies. The presence of the nitro groups in NACs cause the aromatic ring to have an electron-deficient character. This means NACs can interact with electron-rich monomers via $\pi-\pi$ interaction and charge-transfer interaction. The methyl group of trinitrotoluene (TNT) can even be deprotonated e.g., by basic amines in the Brønsted-Lowry acid-base reaction. 
Table 1. Explosives and explosive markers used as template molecules.

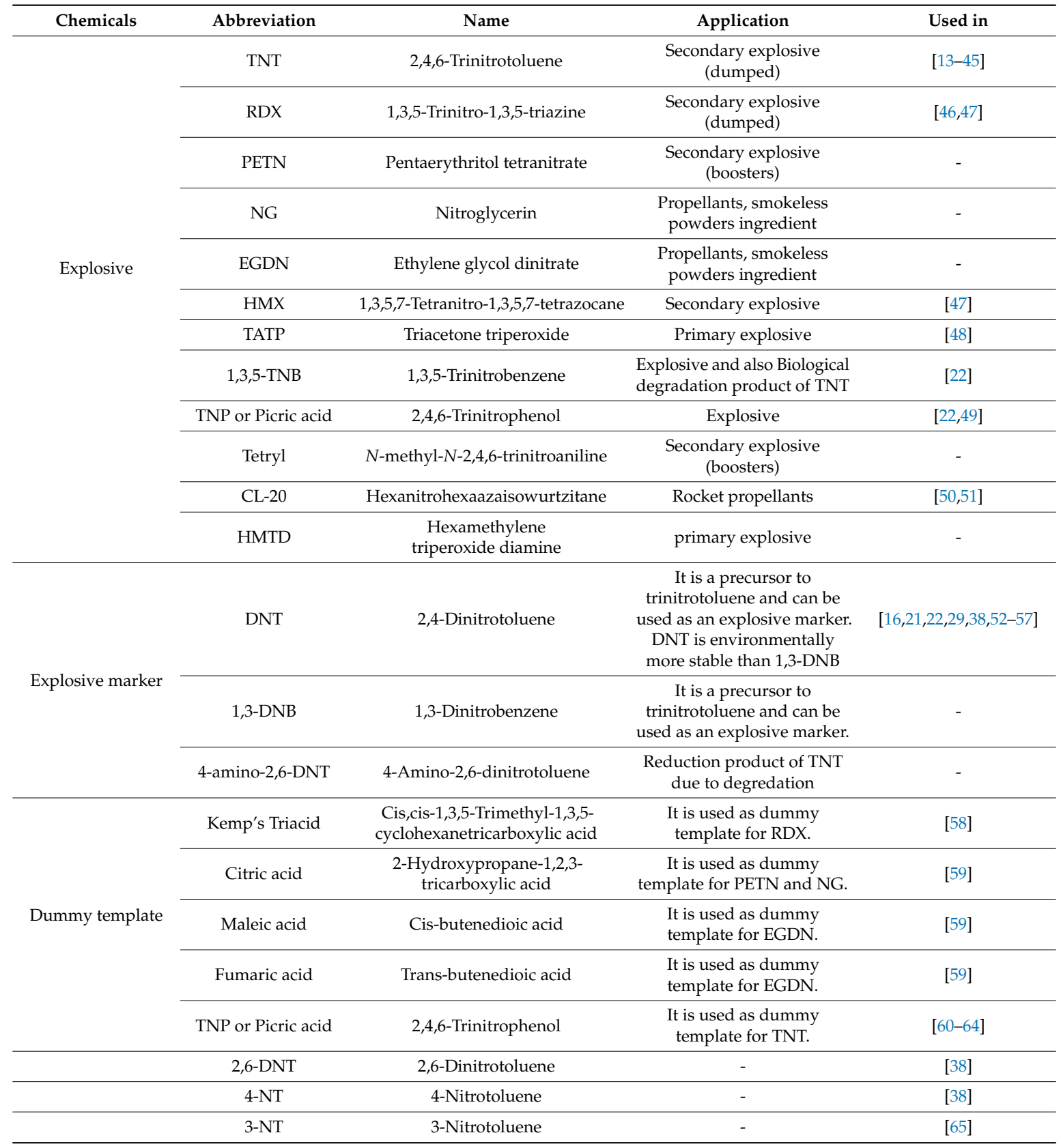

Different innovative synthesis and modification strategies have been developed to increase the efficiency of MIPs' performance. For example, and in some studies, structural-analogs have been used, as dummy templates for explosives (Table 1). Using dummy templates can help to prevent a bleeding effect after polymerization or even more effective formation of template-monomer complex before polymerization. The sizes of polymer particles have also been reduced to nanoscales and the porosity of the polymer matrix has been increased. These changes have helped increase the surface-area-to-volume ratio and improve the accessibility of the majority of imprinted cavities and, therefore, increase polymer capacity. This has also simplified the template removal and rebinding processes. In some other studies, polymerization, either on the surface or within the pores of a uniform nanoscale substrate, has also been used to produce more uniform and homogeneous MIP nanoparticles or MIP-modified nanoparticles (detailed MIP synthesis parameters of the published manuscripts are summarized in Table S1). 
Most of the synthesized polymers were used in combination with sensor transducers. The majority of these sensors were either electrochemical or fluorescence sensors due to the fact that NACs can undergo stepwise reduction in an electrochemical reaction or quench the fluorescence emission of nearby fluorophores. An ideal modified sensor must be highly selective, sensitive, fast, robust, inexpensive, and have the ability to be miniaturized. To maximize the reproducibility, sensitivity and stability of MIP sensors, uniform and reproducible porous MIP nanolayers or nanoparticles, which are well adhered to the sensor's surface, are required. It is worth noting that most MIP sensors were evaluated for the explosives in liquid samples. In comparison to liquid samples, the usage of MIP materials for gaseous samples is more limited due to the following reasons: (I) when MIP materials are used in the gas phase, the 3D shape of the recognition sites and spatial orientation of functional groups within them are altered, as the materials are dry. This causes the MIP to lose its selective recognition ability. (II) Most of the widely-used explosives (e.g., TNT) belong to a group of chemicals termed semi-volatile organic compounds with extremely low volatility. However, innovative strategies were also used to develop fluorescence [31] and integrated-optical-waveguide [39,40] sensors for TNT detection in air.

MIPs have also been used for sample preparation and separation purposes (analytical parameters of these methods are summarized in Table S2). They are used to pack columns and solid phase extraction (SPE) cartridges or as an extracting phase in the solid phase microextraction (SPME) method. Like sensors, sample preparation of explosives using MIPs is also largely limited to liquid samples and at ambient temperatures.

Valuable information for commercially available explosives detection methods has been gathered by the Center for Homeland Defense and Security (CHDS) [66], which enables us to have an overview and compare the developed methods throughout this review with those already available in the market. For trace detection of explosives (nitrates, chlorates, bromates, and peroxides)-vapor or particle-portable (1-6.6 kg) or bench-top (53-60 kg) detectors are available. They generally work on the basis of ion mobility spectrometry (IMS) [67], thermo-redox techniques or chemiluminescence, and fluorescence techniques or surface acoustic wave (SAW) method. They can mostly detect explosives between $1 \mathrm{ng}$ to $100 \mathrm{ng}$ as particles and $1 \mu \mathrm{g} \mathrm{m}^{-3}$ to $10 \mu \mathrm{g} \mathrm{m}^{-3}$ as vapor. These portable detectors mostly suffer from interferences and can detect nitrates without classification. However, the bench-top versions can identify many individual explosive compounds with little interference. The response times for all detectors are lower than $60 \mathrm{~s}$. Additionally, they can operate in all expected environments and extreme environments, which must be considered as a critical point for newly developed ideas.

For determination of explosives in water samples, the federal facilities forum, a U.S. environmental protection agency (EPA) group, reported on the field sampling and selecting of on-site analytical methods [68]. In this paper, the authors gathered information from other manuscripts in which e.g., frequency of occurrence of specific explosives in groundwater was assessed by compiling analytical data on water samples collected from military installations. The obtained median levels for explosives using EPA Method 8330 (EPA 1998) were as following: TNT: $\left(15 \times 10^{-9} \mathrm{~mol} \mathrm{~L}^{-1}\right), 1,3,5-\mathrm{TNB}$ : $\left(7 \times 10^{-9} \mathrm{~mol} \mathrm{~L}^{-1}\right), 2$-amino-4,6-dinitrotoluene: $\left(56 \times 10^{-9} \mathrm{~mol} \mathrm{~L}^{-1}\right), 2,4$-DNT: $\left(6.6 \times 10^{-9} \mathrm{~mol} \mathrm{~L}^{-1}\right)$, 4-amino-2,6-dinitrotoluene: $\left(23 \times 10^{-9} \mathrm{~mol} \mathrm{~L}^{-1}\right)$, DNB: $\left(4.6 \times 10^{-9} \mathrm{~mol} \mathrm{~L}^{-1}\right)$, Tetryl: $\left(3.2 \times 10^{-9} \mathrm{~mol} \mathrm{~L}^{-1}\right)$, 2,6-DNT: $\left(0.55 \times 10^{-9} \mathrm{~mol} \mathrm{~L}^{-1}\right)$, RDX: $\left(13.5 \times 10^{-9} \mathrm{~mol} \mathrm{~L}^{-1}\right)$ and HMX: $\left(257 \times 10^{-9} \mathrm{~mol} \mathrm{~L}^{-1}\right)$ [68]. In another study by the U.S. Army, the occurrence and concentration of explosive residues in groundwater were evaluated at open burning open detonation $(\mathrm{OB} / \mathrm{OD})$ sites. The obtained mean values for the detected explosives were as following: TNT: $\left(141 \times 10^{-9} \mathrm{~mol} \mathrm{~L}^{-1}\right)$, RDX: $\left(756 \times 10^{-9} \mathrm{~mol} \mathrm{~L}^{-1}\right), 2,4$-DNT: $\left(77 \times 10^{-9} \mathrm{~mol} \mathrm{~L}^{-1}\right), 2,6-\mathrm{DNT}:\left(71 \times 10^{-9} \mathrm{~mol} \mathrm{~L}^{-1}\right)$, HMX: $\left(1232 \times 10^{-9} \mathrm{~mol} \mathrm{~L}^{-1}\right)$; Tetryl was not detected. In both scenarios, TNT and RDX were detected in most evaluated sample sites. HMX was detected in a small number at a relatively high concentration. 


\section{Sensors}

\subsection{Electrochemical Sensors}

Electrochemical sensors provide various cost-effective and simple platforms, which are relatively easy to modify to sense specific targets in liquid samples. When using electrochemical sensors, the redox activity of nitro groups associated with many explosives can be used for their detection [28]. Nitro groups $\left(-\mathrm{NO}_{2}\right)$ can be reduced to hydroxylamine groups $(-\mathrm{NHOH})$ under acidic conditions. Hydroxylamine groups can also be oxidized, when the applied potential is reversed towards positive voltages [24]. If these reactions occur on the surface of a modified electrode, which specifically binds explosives or explosive markers, the specific detection of these chemicals may be possible.

An electrochemical quartz crystal microbalance (EQCM) is a device that can be used simultaneously as an electrochemical transducer and a mass sensor to monitor either the current response or the mass-change on gold electrode as a result of an electrochemical reaction. Using electropolymerization, the gold electrode of an EQCM was modified with conductive MIP layers using the following template molecules: 2,4-dinitrotoluene (DNT), TNT, 1,3,5-trinitrobenzene (TNB) and 2,4,6-trinitrophenol (TNP) [22]. The modified sensors were then individually connected to a flow-injection-analysis system. For the reduction of each target, a specified negative potential was applied to the modified sensors. However, electrochemical decomposition of MIP layer occurred at -1.00 volt. The developed sensors provide suitable selectivity when the template of one MIP chemosensor was used to test the selectivity of other chemosensors. However, they suffer from a lack of sensitivity and have not been used for real samples (Table 2).

In another study, a commercially available screen printed electrode (SCPE) as an innovative miniaturized electrochemical platform was coated with a thick layer $(200 \mu \mathrm{m})$ of TNT imprinted polymer [23]. Carboxylic acid $\left(-\mathrm{COO}^{-} \mathrm{H}^{+}\right)$groups in the backbone of the polymer were used as an electrolytic medium. Using cyclic voltammetry, reduction and oxidation peaks appeared for TNT using MIP-modified SCPE, while no peak was obtained with another SCPE, which was modified with non-imprinted polymer (NIP). This proved that recognition sites were imprinted within MIP, while NIP inhibited the access of TNT molecules to the working electrode. For quantification purposes, differential pulse voltammetry (DPV) was selected due to the easier identification of peaks at lower concentrations. The selectivity of the developed MIP-modified SCPE was evaluated using organic, anionic, and cationic targets. Among all evaluated organic molecules, only 2,4,6-trinitrobenzoic acid (TNBA) was detected, which has a similar structure to TNT. Additionally, the MIP-modified SCPE detected $\mathrm{Cu}^{2+}$ due to the cation-exchange nature of the polymer. However, the peak-potential of the $\mathrm{Cu}^{2+}$ did not interfere with that for TNT molecules. The results showed that the sensitivity of the bare SCPE and MIP-modified SCPE depends strongly on the acidity, ionic composition and concentration in the solution. After the working parameters were optimized, the sensitivity of the MIP-modified SCPE was higher than that of the MIP-modified EQCM [22] (Table 2). The authors also showed that their MIP-modified SCPE can be used for selective detection of TNT, even in $20 \mu \mathrm{L}$ not-deaerated water sample. In general, commercially available SCPEs are cost-effective and disposable, and their related accessories are portable. These inherent advantages of bare SCPE can make their modified versions an ideal choice for field application. However, the obtained LOD for determination of TNT using the MIP-modified SCPE $\left(0.50 \times 10^{-6} \mathrm{~mol} \mathrm{~L}^{-1}\right)$ is still higher than those mean values, as reported by EPA [68], for TNT concentration in groundwater samples in military installations $\left(15 \times 10^{-9} \mathrm{~mol} \mathrm{~L}^{-1}\right)$ and groundwater samples in open burning open detonation (OB/OD) sites $\left(141 \times 10^{-9} \mathrm{~mol} \mathrm{~L}^{-1}\right)$. 
Table 2. Analytical figures of merit for developed MIP-modified electrochemical, fluorescence and chemiluminescence sensors.

\begin{tabular}{|c|c|c|c|c|c|c|}
\hline Target & $\begin{array}{c}\text { LOD } \\
\left(\mathrm{mol} \mathrm{L}^{-1}\right)\end{array}$ & Sensitivity & $\begin{array}{l}\text { Linear Range } \\
\left(\mathrm{mol} \mathrm{L}^{-1}\right)\end{array}$ & $\begin{array}{l}\text { Analysis } \\
\text { Time }\end{array}$ & Sensor & Ref. \\
\hline TNP & $\begin{array}{l}\text { CA: } 0.69 \times 10^{-3} \\
\text { PM:0.02 } \times 10^{-3}\end{array}$ & $\begin{array}{l}\text { CA: } 7.34 \mu \mathrm{AmM}^{-1} \\
\text { PM: } 27.3 \mathrm{~Hz} \mathrm{mM}^{-1}\end{array}$ & \multirow{4}{*}{$(0.7-5.6) \times 10^{-3}$} & \multirow{4}{*}{$10 \mathrm{~min}$} & \multirow{4}{*}{ EQCM } & \multirow{4}{*}{ [22] } \\
\hline TNT & $\begin{array}{l}\text { CA: } 0.62 \times 10^{-3} \\
\text { PM: } 0.07 \times 10^{-3}\end{array}$ & $\begin{array}{l}\text { CA: } 5.65 \mu \mathrm{A} \mathrm{mM} M^{-1} \\
\text { PM: } 21.4 \mathrm{~Hz} \mathrm{mM}^{-1}\end{array}$ & & & & \\
\hline TNB & $\begin{array}{l}\text { CA: } 0.27 \times 10^{-3} \\
\text { PM: } 0.15 \times 10^{-3}\end{array}$ & $\begin{array}{l}\text { CA: } 6.33 \mu \mathrm{A} \mathrm{mM}^{-1} \\
\text { PM: } 8.6 \mathrm{~Hz} \mathrm{mM}^{-1}\end{array}$ & & & & \\
\hline DNT & PM: $0.76 \times 10^{-3}$ & PM: $1.3 \mathrm{~Hz} \mathrm{mM}^{-1}$ & & & & \\
\hline TNT & $0.50 \times 10^{-6}$ & $25-200 \mu \mathrm{A} \mathrm{mM}^{-1}$ & - & $\approx 3 \mathrm{~min}$ & SCPE & [23] \\
\hline TNT & $1.5 \times 10^{-9}$ & $1.33 \times 10^{4} \mu \mathrm{A} \mathrm{mM}^{-1}$ & $(0.005-1) \times 10^{-6}$ & $\approx 11 \mathrm{~min}$ & $\mathrm{CPE}$ & [24] \\
\hline TNT & $0.5 \times 10^{-9}$ & $4.423 \times 10^{4} \mu \mathrm{A} \mathrm{mM}^{-1}$ & $(0.001-0.13) \times 10^{-6}$ & $\approx 5 \min$ & $\mathrm{CPE}$ & [25] \\
\hline TATP & $0.36 \times 10^{-6}$ & $7.25 \times 10^{1} \mu \mathrm{A} \mathrm{mM}^{-1}$ & $(0.37-199) \times 10^{-6}$ & - & GCE & [48] \\
\hline RDX & $20 \times 10^{-12}$ & $7.1 \times 10^{6} \mu \mathrm{A} \mathrm{mM}^{-1}$ & $(0.1-10) \times 10^{-9}$ & $\approx 15 \mathrm{~min}$ & GCE & [46] \\
\hline DNT & $1.0 \times 10^{-9}$ & $0.6 \times 10^{4} \mu \mathrm{A} \mathrm{mM}^{-1}$ & $(0.0022-1) \times 10^{-6}$ & $\approx 11 \mathrm{~min}$ & GCE & [52] \\
\hline TNT & $1.3 \times 10^{-8}$ & $3.0205 \times 10^{2} \mu \mathrm{A} \mathrm{mM}^{-1}$ & $(0.04-3.2) \times 10^{-6}$ & $30 \mathrm{~s}$ & Modified GCE & [27] \\
\hline TNT & $3.5 \times 10^{-18}$ & $-1.148 \times 10^{12} \Omega \mathrm{mM}^{-1}$ & $(0.01-10000) \times 10^{-15}$ & $\approx 35 \mathrm{~min}$ & Modified GCE & [26] \\
\hline TNT & $2.0 \times 10^{-10}$ & $\approx 6.1 \times 10^{3} \mu \mathrm{A} \mathrm{mM}^{-1}$ & - & $\approx 1.5 \mathrm{~min}$ & $\begin{array}{l}\text { Modified gold } \\
\text { electrode }\end{array}$ & [28] \\
\hline $\begin{array}{l}\text { TNT } \\
\text { DNT }\end{array}$ & $\begin{array}{l}\text { TNT: } 4.07 \times 10^{-5} \\
\text { DNT: } 3.01 \times 10^{-5}\end{array}$ & - & - & $\begin{array}{l}\text { TNT: } 1 \mathrm{~min} \\
\text { DNT: } 10 \mathrm{~min}\end{array}$ & $\begin{array}{l}\text { QD-MIP } \\
\text { particle }\end{array}$ & [29] \\
\hline DNT & $3.01 \times 10^{-6}$ & $\mathrm{a} \approx 20.27 \mathrm{mM}^{-1}$ & $(5.5-82.4) \times 10^{-6}$ & $\approx 30 \mathrm{~min}$ & $\begin{array}{l}\text { QD-MIP } \\
\text { porous film }\end{array}$ & [53] \\
\hline TNT & $0.28 \times 10^{-6}$ & $\mathrm{a} \approx 61.2 \mathrm{mM}^{-1}$ & $(0.8-30) \times 10^{-6}$ & $\approx 10 \mathrm{~min}$ & QDs@MIP & [61] \\
\hline TNT & $1.5 \times 10^{-8}$ & ${ }^{\mathrm{a}} \approx 1818 \mathrm{mM}^{-1}$ & $(5-60) \times 10^{-8}$ & $\approx 10 \mathrm{~min}$ & $\begin{array}{c}\text { Red-QDs@ } \\
\text { green-QDs/MIP }\end{array}$ & [62] \\
\hline TNT & $1.7 \times 10^{-8}$ & a $940 \mathrm{mM}^{-1}$ & $(5-200) \times 10^{-8}$ & $4 \mathrm{~min}$ & QD-NH $2-\mathrm{MIP}$ & [63] \\
\hline TNP & $0.87 \times 10^{-12}$ & $13.7 \times 10^{6} \mathrm{mM}^{-1}$ & $(0.87-89) \times 10^{-12}$ & - & $\begin{array}{l}\text { MIP-modified } \\
\text { ITO electrode }\end{array}$ & [49] \\
\hline TNT & $30 \times 10^{-12}$ & $2.16 \times 10^{6} \mathrm{mM}^{-1}$ & $(8.81-22000) \times 10^{-11}$ & $\approx 18 \mathrm{~s}$ & $\begin{array}{c}\text { Imprinted } \\
\text { QDs@SiO } \\
\text { as catalyzer }\end{array}$ & [32] \\
\hline
\end{tabular}

${ }^{\mathrm{a}} \mathrm{K}_{\mathrm{sv}}$ in Stern-Volmer plot; CA: Chronoamperometry; PM: Piezoelectric microgravimetry.

The surfaces of other known electrochemical electrodes e.g., carbon electrodes including carbon paste electrodes (CPEs) and glassy carbon electrodes (GCEs) and traditional gold electrodes have been modified with explosive-imprinted polymers using innovative strategies.

Alizadeh's group introduced a simple and effective method to modify CPE material with imprinted polymer particles (synthesized by precipitation polymerization) for sensitive determination of TNT [24]. Later, they proposed a new variation [25] in which methacrylic acid-modified magnetic nanoparticles $\left(\mathrm{Fe}_{3} \mathrm{O}_{4} \approx 22 \mathrm{~nm}\right)$ were coated with a TNT-imprinted organic nanolayer $(\approx 100 \mathrm{~nm})$. The modified magnetic particles were suspended in water samples and then collected and analyzed with a magnetic $\mathrm{CPE}$. In both studies, the interference caused by various ions and molecules were examined. The results showed that the $5-7 \%$ relative-error of TNT signal happened when interference concentrations were greater than or equal to 30 times the TNT concentration. Both methods allowed sensitive determination of TNT in water samples (Table 2). However, as the former MIP-modified CPE proposed by Alizadeh [24] is easy to produce and can be regenerated by simply rubbing the used electrode on a paper, this strategy may prove to be more successful for the production of commercial sensors. 
GCEs, which have lower porosity and higher mechanical rigidity than CPEs, have been also modified with explosives imprinted polymers using a range of different methodologies by different research groups [26,27,46,48,52].

Using a simple strategy, triacetone triperoxide (TATP)-imprinted sites were created among a uniform organic layer on the surface of GCE during electropolymerization of pyrrole [48]. The synthesized layer was shown to be selective towards TATP in the presence of a group of other explosives including pentaerythritol tetranitrate (PETN), TNT, 1,3,5-trinitro-1,3,5-triazine (RDX) and 1,3,5,7-tetranitro-1,3,5,7-tetrazocane (HMX). Although this sensor is easily prepared and shows a wide linear-range, it is less sensitive than the other modified GCEs presented in this review (Table 2).

Recently, Alizadeh et al. [46] reported a highly sensitive GCE modified with a mixture of RDX-imprinted polymer nanoparticles and multiwalled carbon nanotubes (MWCNTs). The combination of the unique electronic features of the MWCNTs and the selectivity and porosity of the MIP nano-spheres enabled sensitive (LOD: $20 \times 10^{-12} \mathrm{~mol} \mathrm{~L}^{-1}$ ) and selective determination of RDX in water samples (Table 2). The obtained LOD could satisfactorily support RDX measurement in groundwater samples in military installations and in open burning open detonation (OB/OD) sites, which have, respectively, mean values as following: $13.5 \times 10^{-9} \mathrm{~mol} \mathrm{~L}^{-1}$ and $756 \times 10^{-9} \mathrm{~mol} \mathrm{~L}^{-1}$ (reported by EPA [68]). In this study, the preparation procedure is relatively simple and the sensor response towards RDX is 3.5 times higher than that of HMX and eight times more than TNT.

Using another strategy (Figure 1a), the surfaces of carboxylic acid functionalized MWCNTs were preliminary modified with a DNT imprinted polymer using a comparably complicated procedure [52]. MIP-modified MWCNTs were then mixed with a chitosan solution, which was dropped and dried on the surface of a GCE. The sensor response towards DNT was at least three times higher than that of the other analog chemicals, including TNT, TNB and 1,3-dinitrobenzene (DNB) each at $0.3 \mu \mathrm{M}$. In addition, the evaluated targets did not interfere with the DNT signal (at $0.1 \mu \mathrm{M})$, even when their concentrations were three times higher than the concentration of DNT. Despite the success of this method at selectively detecting the target molecule, the modification procedure is more complicated than the previous GCE method presented [46] and the sensitivity is not as high.

Nie et al. prepared a GCE modified with gold nanoparticles (AuNPs) and further coated it with a two-dimensional imprinted monolayer (2D-MIM) based on the self-assembled monolayers (SAMs) preparation procedure [27]. The 2D-MIMs can provide better site accessibility and lower mass-transfer resistance. Modified sensor for TNT provided a LOD $\left(1.3 \times 10^{-8} \mathrm{~mol} \mathrm{~L}^{-1}\right)$, which enables its application for groundwater samples in open burning open detonation (OB/OD) sites, which contain a relatively high concentration of TNT (mean value: $14.1 \times 10^{-8} \mathrm{~mol} \mathrm{~L}^{-1}$ [68]). The sensor's selectivity was calculated by dividing the obtained peak currents $\left(\mathrm{I}_{\mathrm{MIP}} / \mathrm{I}_{\mathrm{NIP}}\right)$ for TNT and its structural analogs each at $2.5 \mu \mathrm{M}$ (TNT: 4.91, TNB: 1.36, DNT: 1.49 and DNB: 1.27). The optimized method was used successfully for the determination of TNT in spiked wastewater and river water samples. However, a 2D-MIMs modified sensor can also suffer from a lack of stability, as the film is not cross-linked and therefore this methodology may not be able to deliver a rugged sensor.

In another study, a complex procedure (Figure 1b) was used to modify a GCE with a layer of C60-AuNPs, which act as a porous conductive and biocompatible mediator. A further modification was made, whereby an amino-aptamer acted as the receptor within the imprinted cavity of the MIP layer, which was coated on the nanoparticles producing a hybrid receptor [26]. Despite the ultra-sensitivity obtained for the developed sensor $\left(-1.148 \times 10^{12} \Omega \mathrm{mM}^{-1}\right.$ with LOD: $3.5 \times 10^{-18} \mathrm{~mol}$ $\left.\mathrm{L}^{-1}\right)$, the preparation procedure is complicated. Furthermore, aptamers, which play a key role in the selectivity of this modified sensor, are inherently sensitive to harsh environmental conditions that restrict their comprehensive application. Besides, reported results, which are many orders of magnitude better than anything else in the field, may not promise a commercial product for field application.

AuNPs were also used by Riskin et al. [28] to coat a 4-aminothiophenol-modified gold electrode (Figure 1c). After the AuNPs were electropolymerized onto the surface of the electrode, they were joined together using bisaniline bridging units. Due to the $\pi-\pi$ interaction of the bridging units with 
NACs, the modified sensor showed relative selectivity and sensitivity towards TNT in comparison to DNT, as TNT is a stronger $\pi$-acceptor. The authors showed that electropolymerization in the presence of picric acid, as a dummy template for TNT, could imprint the composite layer and therefore increase the adsorption capacity and sensitivity of the modified sensor due to the additional steric confinement of target molecules [28]. The sensor's selectivity was also increased by about 10-fold after imprinting the composite layer. This method offers a modified sensor with high selectivity using a relatively simple methodology. Additionally, it provides a sensitive and fast sensor for determination of TNT in water samples (Table 2).

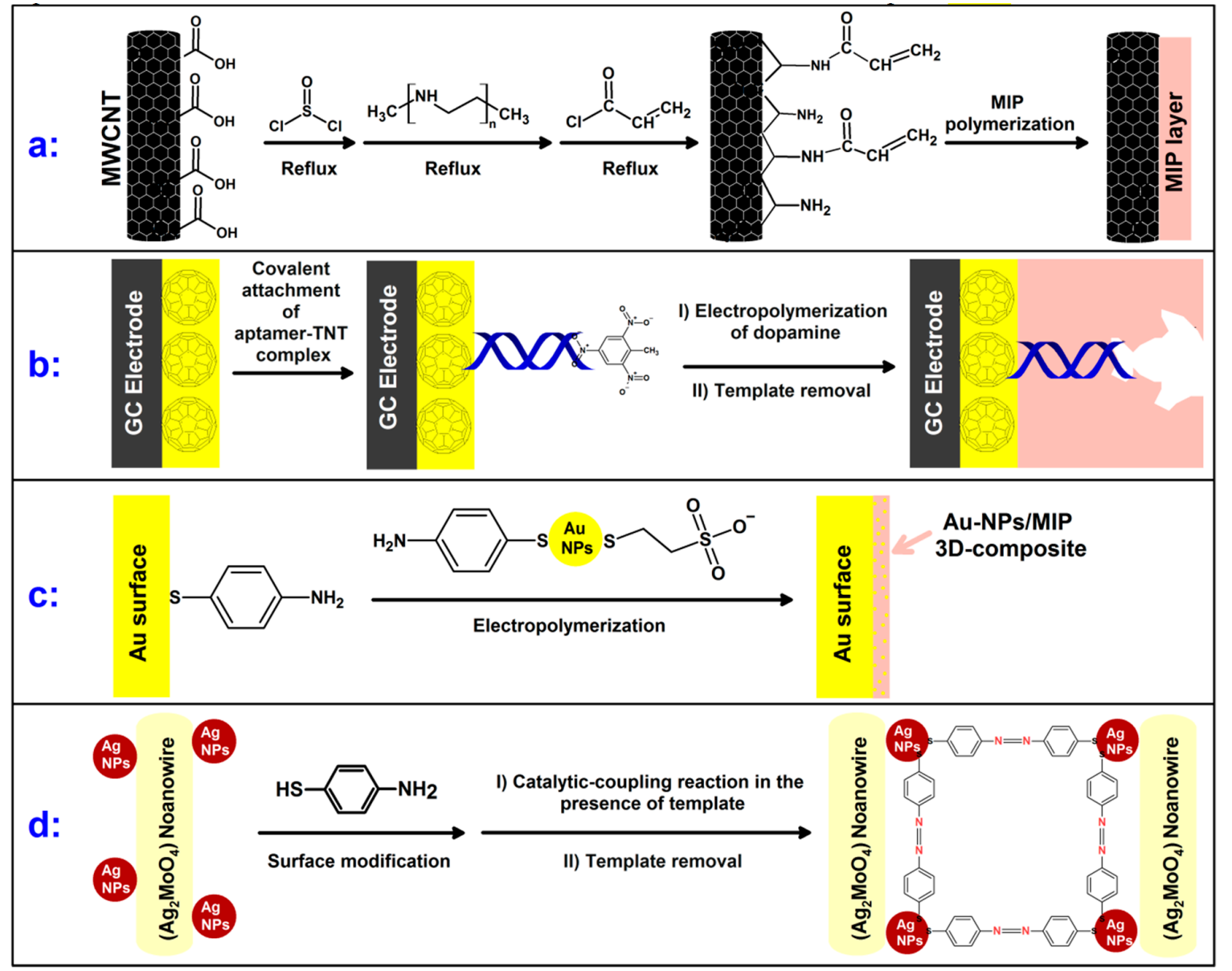

Figure 1. Developed synthesis strategies for explosive imprinted polymers used in electrochemical sensors (a, b and $\mathbf{c}$ in [52], [26] and [28], respectively), surface plasmon resonance sensors (c in [58,59,64]) and surface-enhanced Raman scattering sensor (d in [36]).

\subsection{Fluorescence and Chemiluminescence Sensors}

Nitrated explosives are able to quench the emission of nearby excited fluorophore species due to photoinduced electron transfer between the fluorophore and the nitrated explosive molecule [29,49]. MIP-modified fluorescence sensors can be prepared either by covalent attachment/physical encapsulation of quantum dots (QDs) or by using fluorophore functional-monomers.

Non-uniform TNT- and DNT-imprinted polymer microparticles $(\leq 20 \mu \mathrm{m})$ were prepared using bulk polymerization [29]. Then, the carboxylic acid side groups of the MIP particles were activated to enable them to react covalently with the amine-functionalized CdSe quantum dots (CdSe QD- $\mathrm{NH}_{2}$ ) $\left(\lambda_{\mathrm{em}} 605 \mathrm{~nm}\right)$ in a zero-length cross-linking reaction. However, the selectivity of the developed sensors was not systematically evaluated. Despite the relatively simple methodology proposed, 
the limit-of-detections (LODs) obtained using this method were high (Table 2) due to the structure of the polymer particles.

Therefore, in a new study [53], a porous DNT-imprinted polymer layer was synthesized on the glass slide using bulk polymerization. The idea was to carry out the polymerization in the void spaces among silica particles $(\approx 0.213 \mu \mathrm{m})$, which were coated on a glass slide. After polymerization, the silica particles were removed and the polymer surface was labeled with QD- $\mathrm{NH}_{2}$ using the same procedure described by Stringer et al. [29]. Although the LOD was improved by a factor of ten for DNT, the sample incubation time was increased from $10 \mathrm{~min}$ to $30 \mathrm{~min}$ (Table 2). The results showed that the increased porosity still could not provide a sufficiently sensitive fluorescence sensor. Further reduction in the size of polymer particle to the nanoscale could be investigated to improve the sensor's sensitivity. For example, Zhang's group $[17,30]$ has proposed an interesting synthesis strategy to prepare MIPs that have polymer particles at the nanoscale. The idea was to carry out polymerization within the nanopores of a sacrificial-substrate to produce MIPs as nanowires or nanotubes for TNT. These materials have not been used in combination with a sensor or a sample preparation method, which can be evaluated in a new study.

$\mathrm{Xu}$ et al. [61] reported a fluorescence sensor in which CdTe QDs $\left(\lambda_{\mathrm{em}} 530 \mathrm{~nm}\right)$ were dispersed within a silica nanoparticle, which was subsequently covered with an imprinted silica layer using TNP as the dummy template for TNT (Figure 2a). Three synthesis methods (reverse-microemulsion, Stöber and seed-growth methods) were compared and the seed-growth method, which combined the advantages of the other two methods, produced QDs@MIP with the best fluorescence functionality. These modified particles were used for selective determination of TNT in soil samples. However, the sensitivity of the prepared sensor was weak due to the recognition-site's poor accessibility and also the low probability that each recognition site is surrounded by QDs.

Two modifications to this sensor were proposed in a further article from $\mathrm{Xu}$ et al. [62]. Firstly, a mesoporous structure (pore diameters: $2-15 \mathrm{~nm}$ ) was created in the imprinted shell layer using aggregated ionic surfactants as supramolecular templates in the co-condensation reaction. Secondly, the ratiometric fluorescence technique was used in which red CdTe QDs $\left(\lambda_{\mathrm{em}} 640 \mathrm{~nm}\right)$ were dispersed within the silica nanoparticle and green CdTe QDs $\left(\lambda_{\mathrm{em}} 540 \mathrm{~nm}\right)$ were dispersed in the mesoporous imprinted silica shell. The red CdTe QDs were not in direct contact with external TNT molecules and their wavelength was monitored as a reference signal (Figure 2b). Adding these two modifications, the detection limit of QDs@MIP sensors improved from $\mu \mathrm{M}$ [61] to nM [62]. In addition, a more reliable qualitative visual assessment of the sensor was also possible [62].

A further optimization of these sensors was performed [63], whereby the imprinting process was simplified. This was achieved by using the amine-functionalized QDs as the functional monomer. Cetyltrimethylammonium bromide (CTAB) was again used as the directing agent, to synthesize the previously described mesoporous polymer (Figure 2c). A further benefit of this change was that the optimized analysis time was reduced from $10 \mathrm{~min}$ to $4 \mathrm{~min}$.

Mesoporous structures, this time in combination with macro- and microporous structures, were used to fabricate a fluorescence gas-sensor, which was used in a batch-mode for the fast (response time $\approx 120 \mathrm{~s}$ ) determination of TNT molecules in gas phase [31]. In this study, polymerization of mesoporous organosilicas was performed in the void spaces of a close-packed, face-centered cubic arrangement of monodisperse polystyrene (PS) microspheres (diameter of each $510 \mathrm{~nm}$ ). After the template removal (PS as the macro-structure template; aggregated ionic surfactants as the meso-structure template; TNT as the molecular template), TNT-imprinted recognition sites remained within the mesoporous structure in the macropore walls (Figure 2d). This hierarchically synthesized meso-macro-porous structure enabled fast and easy access to the imprinted cavities due to the higher surface areas and larger pore volumes [31]. Additionally, by replacing the fluorophore functional-monomer with a urea-functionalized dye, the selectivity of the synthesized porous layer was considerably improved. However, these materials have not been systematically evaluated to show their selectivity and sensitivity. 


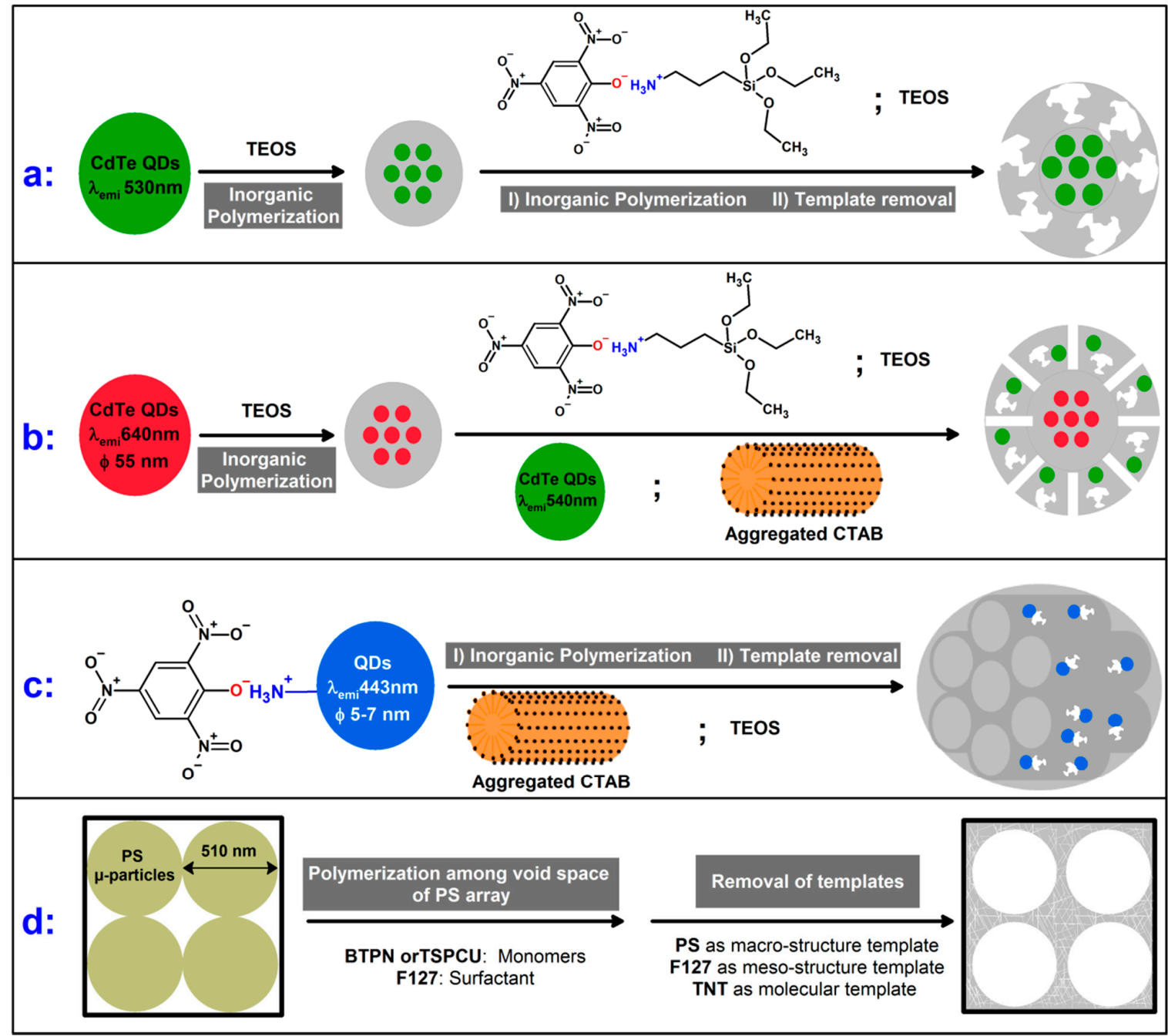

Figure 2. Developed synthesis strategies for explosive imprinted polymers used in fluorescence sensors (a, b, c and d in [61], [62], [63] and [31], respectively). TEOS: Tetraethyl orthosilicate; CTAB: Cetyltrimethylammonium bromide; PS: Polystyrene; BTPN: 1,5-Bis (allyloxy)naphthalene; TSPCU: Triethoxysilylated Coumarin, F 127: Pluronic F127.

In contrast to all of the previously mentioned materials, which rely on a quenching mechanism to cause a change in the fluorescence, it has recently been shown [49] that the rigid polymer-matrix of MIP could facilitate fluorescence emission in the presence of nitrated explosive molecules. In this study, the surface of an indium-tin oxide glass-slide electrode was modified with TNP-imprinted polymer (TNP was used as template and target molecule) using electropolymerization. This polymer emitted a new fluorescence peak at $\approx 670 \mathrm{~nm}$, when it was wetted with TNP solutions [49]. Compared to the evaluated interferences (TNT and phenol), the modified sensor showed the highest sensitivity towards TNP, which was five times more than that for TNT and six times more than that for phenol. However, it was not applied for a real sample measurement.

Another highly sensitive sensor was developed for the determination of TNT in water and soil samples using an indirect approach that measured the weak chemiluminescence (CL) emission of alkaline $\mathrm{KMnO}$ 4/rhodamine B system [32]. In this study, ZnO QDs were synthesized and dispersed within TNT-imprinted silica nanoparticles using a similar approach to that of $\mathrm{Xu}$ et al. [61]. After template removal, the washed QDs@MIP nanoparticles catalytically amplified the weak CL emission. In the presence of TNT molecules, the imprinted nanoparticles lost their catalytic activity and the intensity of the CL was decreased. This reduction was used to calculate the TNT concentration [32]. 
Only one of the structural analogs (TNP) used for selectivity evaluation of the sensor caused a signal change $\left(\right.$ Signal $_{\mathrm{TNT}}: \approx 460$ and Signal $_{\mathrm{TNP}}: \approx 60$ ), showing that the sensor selectively detected TNT. Additionally, TNT could even be efficiently measured in the presence of a variety of different ions at high concentrations.

\subsection{Surface Plasmon Resonance (SPR) and Localized Surface Plasmon Resonance (LSPR) Sensors}

In SPR sensors, a thin metal layer is modified on one side (sensing side) and then irradiated from the other side (detection-side) with monochromatic light at different angles. When the incident light has sufficient momentum and strikes the metal surface at the correct angle of incidence, the oscillation mode of surface electrons can become coupled with that of the electromagnetic wave, causing the light to be absorbed. This specific resonance angle is sensitive to the changes in the surrounding environment of the sensing-side. As the adsorption of molecules on the sensing-side of the metal layer can shift the angle at which the light is absorbed, a suitably modified sensor could be used for the specific detection of a target molecule.

In the typical Kretschmann configuration, a prism is used to effectively couple the irradiated electromagnetic waves with the oscillation mode of the surface electrons in metal [69]. The prism was replaced with plastic optical fibers (POFs) $[33,34]$ to reduce the size and cost of device, to enable remote sensing and to enhance the sensitivity of the sensor due to multiple interactions between the light and the detection side occurring in the optical fiber. One side of a POF was polished to produce a D-shaped POF and then coated successively with a photoresist buffer film, a thin gold layer, and a TNT-imprinted polymer layer [33]. The sensor showed low-sensitivity (Table 3), which also made it difficult to evaluate the selectivity of the modified MIP layer.

In order to increase the sensitivity of this SPR sensor, a D-shaped POF was covered directly with a composite layer containing a TNT-imprinted polymer and gold nanostars [34]. These metallic nanoparticles are of comparable or smaller size than the wavelength of incident light and therefore can confine and amplify the SPR, termed LSPR. The sensitivity of the LSPR sensor [34] (Table 3) was $\approx 3$-fold that of the previously reported SPR sensor [33]. Additionally, it was shown that the sensitivity of the MIP-modified LSPR sensor can be further increased up to $\approx 10$-fold when the substrate was tapered before modification [34]. Despite the increase in sensitivity as a result of this modification, these sensors still suffer from low sensitivity relative to the following SPR sensors.

Electronic coupling of LSPR to SPR was used to produce ultrasensitive, fast and selective SPR sensors for TNT [64], RDX [58], PETN [59], nitroglycerin (NG) [59] and ethylene glycol dinitrate (EGDN) [59] after a surface modification of the SPR gold surface with MIP/Au-NPs composite nano-layers (9.7 nm [64] and 10-12 nm [58]). These sensors were prepared by electropolymerization of AuNPs onto the surface of SPR sensors in the presence of the following dummy templates: picric acid as dummy template for TNT [64], Kemp's Triacid for RDX [58], citric acid for PTEN and NG [59] and maleic acid or fumaric acid for EGDN [59]. Interestingly, citric acid as a dummy template could imprint the Au NPs/polymer composite layer for PETN, while succinic acid, fumaric acid and even the stereoisomer isocitric acid led to imprinted sites of poor affinity for this explosive [59], suggesting that the choice of dummy template is of vital importance.

\subsection{Surface-Enhanced Raman Scattering (SERS)}

In Raman scattering, light is inelastically scattered as it interacts with molecules. The energy change of the scattered light can be used as the structural fingerprint for the molecule under investigation. In SERS, Raman scattering is strongly enhanced when the target analytes are in proximity of metallic nanoparticles or SERS-active nanometer-scale patterning grid surfaces. The gold surface of Klarite, which is a commercial SERS-active substrate, was coated with a TNT-imprinted inorganic film (7-12 $\mu \mathrm{m})$ using the sol-gel process to produce a selective sensor [35]. The sensor was neither fast nor sensitive (Table 3). This sensor was, however, stable for at least six months, which was presented as the highlight of this study. 
To produce a sensitive SERS sensor with stable signals, a novel SERS substrate composed of silver nanoparticles coated on silver molybdate nanowires (Ag-SMNs) was introduced and modified with TNT-imprinted sites between the SERS-active nanowires [36] (Figure 1d). Using this new SERS substrate, the LOD was reduced from $\mu \mathrm{M}$ [35] to $\mathrm{pM}$ [36]. However, these sensors have not been used for TNT measurement in real samples.

Table 3. Analytical figures of merit for developed MIP-modified SPR, LSPR, SERS, IOW and QCM sensors.

\begin{tabular}{|c|c|c|c|c|c|c|}
\hline Target & $\begin{array}{c}\text { LOD } \\
\left(\mathrm{mol} \mathrm{L}^{-1}\right)\end{array}$ & Sensitivity & $\begin{array}{l}\text { Linear Range } \\
\left(\mathrm{mol} \mathrm{L}^{-1}\right)\end{array}$ & $\begin{array}{l}\text { Analysis } \\
\text { Time }\end{array}$ & Sensor & Ref. \\
\hline TNT & $51 \times 10^{-6}$ & $27 \mathrm{~nm} \mathrm{mM}^{-1}$ & $(83-130) \times 10^{-6}$ & $5 \mathrm{~min}$ & $\begin{array}{l}\text { SPR/MIP } \\
\text { layer-Gold } \\
\text { layer-POF }\end{array}$ & [33] \\
\hline TNT & $\begin{array}{l}\text { GNS-MIP/ POF: } \\
2.4 \times 10^{-6} \\
\text { GNS-MIP/tapered } \\
\text { POF: } 0.72 \times 10^{-6}\end{array}$ & $\begin{array}{c}\text { b GNS-MIP/ POF: } \\
85 \mathrm{~nm} \mathrm{mM}^{-1} \\
\mathrm{~b}^{\mathrm{b}} \text { GNS-MIP/tapered POF: } \\
830 \mathrm{~nm} \mathrm{mM}^{-1}\end{array}$ & - & $5 \mathrm{~min}$ & $\begin{array}{l}\text { LSPR/MIP_GNC } \\
\text { layer-POF }\end{array}$ & [34] \\
\hline TNT & $10 \times 10^{-15}$ & $\mathrm{C} \approx 1.2 \times 10^{12} \mathrm{mM}^{-1}$ & $(10-100) \times 10^{-15}$ & $\approx 15 \mathrm{~s}$ & $\begin{array}{l}\text { SPR-LSPR/Gold } \\
\text { layer-Prism }\end{array}$ & [64] \\
\hline RDX & $12 \times 10^{-15}$ & $\mathrm{C} \approx 0.4 \times 10^{12} \mathrm{mM}^{-1}$ & $\approx(12-300) \times 10^{-15}$ & $\approx 15 \mathrm{~s}$ & $\begin{array}{l}\text { SPR-LSPR/Gold } \\
\text { layer-Prism }\end{array}$ & [58] \\
\hline $\begin{array}{l}\text { PETN } \\
\text { NG } \\
\text { EGDN }\end{array}$ & $\begin{array}{l}\text { PETN: } 200 \times 10^{-15} \\
\text { NG: } 20 \times 10^{-12} \\
\text { EGDN: } 400 \times 10^{-15}\end{array}$ & $\begin{array}{l}\text { PETN: }{ }^{\mathrm{C}} \approx 7.4 \times 10^{9} \mathrm{mM}^{-1} \\
\text { NG: }{ }^{\mathrm{C}} \approx 0.071 \times 10^{9} \mathrm{mM}^{-1} \\
\text { EGDN: }^{\mathrm{C}} \approx 3.5 \times 10^{9} \mathrm{mM}^{-1}\end{array}$ & $\begin{aligned} \mathrm{P}: & \approx(0.2-8) \times 10^{-12} \\
\mathrm{~N} & \approx(20-400) \times 10^{-12} \\
\mathrm{E} & : \approx(0.2-5) \times 10^{-12}\end{aligned}$ & $\approx 15 \mathrm{~s}$ & $\begin{array}{l}\text { SPR-LSPR/Gold } \\
\text { layer-Prism }\end{array}$ & [59] \\
\hline $\mathrm{TNT}$ & $3 \times 10^{-6}$ & $\mathrm{D} \approx 4 \times 10^{4} \mathrm{mM}^{-1}$ & $\approx(?-5) \times 10^{-5}$ & $\begin{array}{l}\text { Incubation } \\
\text { time: } 24 \mathrm{~h}\end{array}$ & SERS & [35] \\
\hline TNT & $1 \times 10^{-12}$ & - & $(1-10000) \times 10^{-11}$ & $\approx 60 \mathrm{~s}$ & SERS & [36] \\
\hline TNT & e 5 ppb V & $0.13 \times 10^{12} \mathrm{mM}^{-1}$ & e $(4-10)$ ppb V & $100 \mathrm{~s}$ & IOW & [39] \\
\hline TNT & e 2.4 ppt V & $8 \times 10^{-4}\left(\right.$ ppt V) $^{-1}$ & e $(20-140)$ ppt V & $120 \mathrm{~s}$ & IOW & [40] \\
\hline DNT & - & $\approx 900 \mathrm{~Hz} \mathrm{mM}^{-1}$ & $(20-100) \times 10^{-6}$ & $\approx 200 \mathrm{~min}$ & QCM & [54] \\
\hline
\end{tabular}

\subsection{Colorimetric Sensors}

Colorimetric sensors are able to change their color in response to their surrounding environment. This type of visual detection is of great interest to the military and at security checkpoints due to the ease of reading and interpreting the signal. Photonic crystals (PCs) are biomimetic colorimetric substrates, which are composed of periodic optical nanostructures and reflect certain wavelengths of light depending on the angle of incident light, the average refractive index, and structural spacing of nanostructure constituents of PCs (Bragg-Snell law).

Lu et al. [37] synthesized monodisperse TNT-imprinted polymer particles (ø $210 \mathrm{~nm}$ ) using emulsion polymerization. Then, the polymer particles were self-assembled on a glass slide to produce a three-dimensional (3D) close-packed film. Afterwards, an adhesive tape was pressed on the prepared film and the glass slide was removed. The color of the MIP-modified film on the adhesive tape changed from green to red in the presence of TNT molecules in an optimized solution $(0 \rightarrow 20 \mathrm{mM})$. Although this sensor was not sensitive, it showed high stability of up to three years.

Building on their previous work, an array of MIP-modified films on adhesive tapes in combination with principal component analysis was used to create "radar" patterns for detection of target compounds [38]. In this study, the same procedure was used to prepare a range of adhesive tapes modified with TNT-, DNT-, 2,6-dinitrotoluene (2,6-DNT)- and 4-nitrotoluene (4-NT)-imprinted polymer particles. 
Although this idea could provide a promising avenue to produce detection kits for preliminary identification of explosives, these sensors do not provide a fast response and still suffer from low sensitivity.

\subsection{Integrated-Optical-Waveguide (IOW)}

Attenuation or phase change of a propagated wave through a cylindrical or planer substrate with total internal reflection characteristics depends on the near-surface composition of the substrate. When the thickness of the substrate is reduced to the dimensions of propagated wave, the substrate is termed an IOW and sensors made using IOWs show greater sensitivity than the thicker substrate.

Edmiston's group has studied the effectiveness of sensors using IOWs both for TNT detection in air in relation to attenuation and phase shift. In one study, a planar IOW substrate $\left(\mathrm{SiO}_{2} / \mathrm{TiO}_{2}\right.$ glass layer, thickness $0.8-1.0 \mu \mathrm{m})$ was coated with TNT-imprinted silica layer $(0.3-1.0 \mu \mathrm{m})$ using dip-coating in sol solution [39]. Using the same coating method, a waveguide interferometer was coated with TNT-imprinted silica layer $(0.2,36 \mathrm{~nm})$ [40]. Attenuation of total reflection (ATR) at $530 \mathrm{~nm}$ [39] and phase shift for $633 \mathrm{~nm}$ [40] were used for the sensitive determination of vapor-phase TNT (Table 3). Using these sensors in the gas phase, TNT molecules were attached irreversibly to the sensor, which was presented as an advantage when using prolonged sampling times and for extremely low concentrations [39,40]. The modified sensors responded suitably, even at high relative-humidity up to $50 \%$ [39] and 55\% [40]. In addition, high concentrations of volatile compounds (which were emitted from the gasoline and cologne containers) did not affect the TNT detection, although they slowed the response time [39].

\subsection{Quartz Crystal Microbalance (QCM)}

In order to detect TNT molecules in the gas phase, two QCM sensors were coated with MIP layers by UV polymerization [41,42]. Different MIP layer thicknesses were obtained, depending on the covering methods as follows: $20-500 \mathrm{~nm}$ by manual coating method, $3300 \mathrm{~nm}$ by automated nano-plotter and 500-3000 $\mathrm{nm}$ via spin coating. Although little evidence regarding either the selectivity or sensitivity of the sensors was presented, the major drawback of this approach was the long response time. As TNT detection in the gas phase is challenging, the idea of a MIP-modified QCM may still prove effective if further developed e.g., by using porous nanostructured MIPs.

For liquid samples, the gold surface of a QCM was modified with a two-dimensional molecularly imprinted monolayer (2D-MIM) [54], using a very similar approach described by Nie et al. [27]. In this study [54], butanethiol in ethanol was used to prepare a self-assembled monolayer in the presence of DNT molecules. In general, a 2D-MIM modified sensor suffers from a lack of stability. Additionally, this modified QCM sensor is neither fast nor sensitive (Table 3) and does not discriminate against molecules with smaller size than the template (e.g., toluene and 4-NT).

\section{Sample Preparation}

There is a great variety of sorbent-based extraction methods that have been developed for the extraction of chemical compounds from liquid samples. However, explosive-imprinted polymers have, so far, only been used either to pack solid phase extraction (SPE) cartridges and columns or to perform SPE in batch mode.

Lordel et al. optimized a synthesis protocol for a DNT-imprinted polymer using sol-gel polymerization with a template/monomer/crosslinker ratio at 1/1/5 [55]. Fifty $\mathrm{mg}$ of the synthesized polymer particles (25-36 nm) were used to fill a $1 \mathrm{~mL}$ SPE cartridge. Using an optimized extraction procedure, the cartridge selectively extracted DNT and TNT from spiked simulated post-blast samples. Although this method recovered DNT (80\%) and 2,6-DNT (68\%) from $15 \mathrm{~mL}$ of a spiked water sample with relatively high percentages, these values for TNT $(46 \%)$ and tetryl $(29 \%)$ were low. Therefore, new sol-gel imprinted polymers were synthesized using the same precursors, but at different template/monomer/crosslinker ratios: $1 / 4 / 20$ and 1/4/30 [56]. SPE cartridges, packed with the new 
synthesized polymers, recovered more than $79 \%$ of all the targets. Building on the previous work, the polymer synthesized at 1/4/30 ratio was used to pack a pre-column and then connected online with a reversed-phase LC system [57]. This online system increased the extraction recoveries to more than $90 \%$.

Xue's group optimized a synthesis protocol with hexanitrohexaazaisowurtzitane (CL-20) as the template molecule using precipitation polymerization [50]. One hundred mg of the optimized MIP was packed in a $1 \mathrm{~mL}$ SPE cartridge and successfully used to selectively extract CL-20 from soil samples. The same group further developed this idea using a new synthesis strategy to increase the porosity of the CL-20 imprinted polymers [51]. In this new study, a modified silica particle was first coated with a MIP shell before being removed using hydrofluoric acid to produce CL-20 imprinted hollow spheres (with an outer diameter of $0.25-0.5 \mu \mathrm{m}$ and a thickness of 30-100 nm). Again, a SPE cartridge packed with MIP sorbent was used, but this time for the extraction of a group of explosives (CL-20, TNT, RDX and HMX) from simulated post-blast samples prepared from motor oil and vacuum pump oil.

In another study by Xue's group, 14 different imprinted polymers were synthesized in the presence of either HMX or RDX as template molecules using precipitation polymerization [47]. RDX is the major byproduct of HMX synthesis and their separation is difficult due to their similar sizes and physical properties. However, a SPE cartridge packed with the optimized MIP could satisfactorily separate them using a flash-chromatography procedure.

In separation science, band-broadening is a major drawback that inversely affects separation efficiency. Trammel et al. [43] synthesized two series of TNT-imprinted periodic mesoporous organosilicas using two different bissilylated organic precursors [43]. They showed that columns which are packed with sorbents with a narrower pore size distribution released the adsorbed targets over a much shorter time.

Ebrahimzadeh et al. showed the advantage of coupling MIP-SPE with other techniques. A batch-mode SPE was coupled with a dispersive-liquid-liquid-microextraction to allow the selective extraction of 3-nitrotoluene (3-NT), whilst increasing the total pre-concentration factor by up to 2800 [65]. In this study, final extracts were analyzed using gas chromatography with a flame ionization detector. Ion mobility spectrometry, a known handheld and portable analytical technique, has also been used to analyze the extracts obtained from a batch-mode SPE [44].

Solid phase microextraction (SPME) is a non-exhaustive sampling and sample preparation method, which has the potential for field application. However, there is just one example where MIP-SPME was developed for use with gaseous samples [45]. In this study, TNT-imprinted polymer powder was coated on a silica support of a SPME fiber using epoxy resin glue. The modified SPME fiber was used to extract TNT molecules from the headspace of a heated sample. The main drawback is the prolonged sampling time (40 $\mathrm{min})$, which is a known difficulty when working with gaseous samples.

\section{Conclusions and Future Perspectives}

This paper reviews the developments in the synthesis and use of selectively imprinted polymers for explosives. MIPs are promising artificial selective sorbents, which can be used in a wide range of conditions; they are relatively stable, simple to produce, and easy to modify for a variety of target molecules. Despite the variety of different approaches in the scientific literature, there are currently no commercially available MIP-modified sensors or sample preparation methods for explosives in liquid samples. For targets in gaseous samples, their implementation is even more challenging, due to changes in the conformation of the binding sites when the polymer is dried. Novel synthesis methods are required to overcome these limitations. New sampling methodologies (e.g., spraying micro-size organic droplets which are loaded with MIP nanoparticles into the gas samples [70]) could help to accelerate the selective and efficient extraction of targets from gas samples. In the future, new, sensitive, low-cost and disposable sensor substrates (e.g., split-ring resonators [71,72]) could be modified with nanoscale MIP materials, as nanolayers or nanoparticles, to create a commercial sensor for explosives. 
Supplementary Materials: The following are available online at http://www.mdpi.com/2073-4360/11/5/888/s1, Table S1. Detailed synthesis-parameters used for MIPs synthesis in published manuscripts. Table S2: Analytical parameters of sample preparation methods for liquid and gaseous samples

Author Contributions: M.Z. wrote the manuscript. All authors contributed efficiently to design and to shape the structure of the manuscript with critical comments and valuable feedbacks. M.C. proofread the manuscript.

Funding: The authors gratefully acknowledge the financial support of the TOXI-Triage project (Tools for detection, traceability, triage and individual monitoring of victims), funded from the European Union's Horizon 2020 (H2020) research and innovation program under Grant Agreement No. 653409.

Conflicts of Interest: The authors declare no conflict of interest.

\section{Abbreviations}

$\begin{array}{ll}\text { Ag-SMNs } & \text { Silver molybdate nanowires } \\ \text { CPE } & \text { Carbon paste electrode } \\ \text { EQCM } & \text { Electrochemical quartz crystal microbalance } \\ \text { GCE } & \text { Glassy carbon electrode } \\ \text { IOW } & \text { Integrated-Optical-Waveguide } \\ \text { LSPR } & \text { Localized surface plasmon resonance } \\ \text { NACs } & \text { Nitroaromatic compounds } \\ \text { 2D-MIMs } & \text { Two-dimensional molecularly imprinted monolayers } \\ \text { PS } & \text { Polystyrene } \\ \text { PCs } & \text { Photonic crystals } \\ \text { POFs } & \text { plastic optical fibers } \\ \text { SPR } & \text { Surface plasmon resonance } \\ \text { SERS } & \text { Surface-enhanced Raman scattering }\end{array}$

\section{References}

1. Wulff, G. Molecular imprinting in cross-linked materials with the aid of molecular templates-A way towards artificial antibodies. Angew. Chem. 1995, 34, 1812-1832. [CrossRef]

2. Wulff, G. Fourty years of molecular imprinting in synthetic polymers: Origin, features and perspectives. Microchim. Acta 2013, 180, 1359-1370. [CrossRef]

3. McCluskey, A.; Holdsworth, C.I.; Bowyer, M.C. Molecularly imprinted polymers (mips): Sensing, an explosive new opportunity? Org. Biomol. Chem. 2007, 5, 3233-3244. [CrossRef] [PubMed]

4. Martin-Esteban, A. Molecularly-imprinted polymers as a versatile, highly selective tool in sample preparation. TrAC-Trends Anal. Chem. 2013, 45, 169-181. [CrossRef]

5. Beyazit, S.; Bui, B.T.S.; Haupt, K.; Gonzato, C. Molecularly imprinted polymer nanomaterials and nanocomposites by controlled/living radical polymerization. Prog. Polym. Sci. 2016, 62, 1-21. [CrossRef]

6. Alizadeh, T.; Ganjali, M.R.; Norouzi, P.; Zare, M.; Zeraatkar, A. A novel high selective and sensitive para-nitrophenol voltammetric sensor, based on a molecularly imprinted polymer-carbon paste electrode. Talanta 2009, 79, 1197-1203. [CrossRef]

7. Zarejousheghani, M.; Schrader, S.; Moder, M.; Lorenz, P.; Borsdorf, H. Ion-exchange molecularly imprinted polymer for the extraction of negatively charged acesulfame from wastewater samples. J. Chromatogr. A 2015, 1411, 23-33. [CrossRef]

8. Alizadeh, T.; Ganjali, M.R.; Zare, M.; Norouzi, P. Development of a voltammetric sensor based on a molecularly imprinted polymer (mip) for caffeine measurement. Electrochim. Acta 2010, 55, 1568-1574. [CrossRef]

9. Zarejousheghani, M.; Schrader, S.; Moder, M.; Schmidt, M.; Borsdorf, H. A new strategy for accelerated extraction of target compounds using molecularly imprinted polymer particles embedded in a paper-based disk. J. Mol. Recognit. 2018, 31. [CrossRef]

10. Zarejousheghani, M.; Schrader, S.; Moder, M.; Mayer, T.; Borsdorf, H. Negative electrospray ionization ion mobility spectrometry combined with paper-based molecular imprinted polymer disks: A novel approach for rapid target screening of trace organic compounds in water samples. Talanta 2018, 190, 47-54. [CrossRef] 
11. Zarejousheghani, M.; Fiedler, P.; Moder, M.; Borsdorf, H. Selective mixed-bed solid phase extraction of atrazine herbicide from environmental water samples using molecularly imprinted polymer. Talanta 2014, 129, 132-138. [CrossRef] [PubMed]

12. Zarejousheghani, M.; Moder, M.; Borsdorf, H. A new strategy for synthesis of an in-tube molecularly imprinted polymer-solid phase microextraction device: Selective off-line extraction of 4-nitrophenol as an example of priority pollutants from environmental water samples. Anal. Chim. Acta 2013, 798, 48-55. [CrossRef] [PubMed]

13. Meng, Z.H.; Zhang, Q.Y.; Xue, M.; Wang, D.; Wang, A. Removal of 2,4,6-trinitrotoluene from "pink water" using molecularly-imprinted absorbent. Propellants Explos. Pyrotech. 2012, 37, 100-106. [CrossRef]

14. Zhu, W.; Wang, C.; Wang, H.; Li, G.T. Theory and simulation of diffusion-adsorption into a molecularly imprinted mesoporous film and its nanostructured counterparts. Experimental application for trace explosive detection. RSC Adv. 2014, 4, 40676-40685. [CrossRef]

15. Zhao, H.X.; Ma, X.L.; Li, Y.B.; Du, R.K.; Zhang, Z.G.; An, F.Q.; Gao, B.J. Selective detection of tnt using molecularly imprinted polymer microsphere. Desalin. Water Treat. 2015, 55, 278-283. [CrossRef]

16. Stringer, R.C.; Gangopadhyay, S.; Grant, S.A. Comparison of molecular imprinted particles prepared using precipitation polymerization in water and chloroform for fluorescent detection of nitroaromatics. Anal. Chim. Acta 2011, 703, 239-244. [CrossRef] [PubMed]

17. Xie, C.G.; Liu, B.H.; Wang, Z.Y.; Gao, D.M.; Guan, G.J.; Zhang, Z.P. Molecular imprinting at walls of silica nanotubes for tnt recognition. Anal. Chem. 2008, 80, 437-443. [CrossRef] [PubMed]

18. Lazau, C.; Iordache, T.V.; Florea, A.M.; Orha, C.; Bandas, C.; Radu, A.L.; Sarbu, A.; Rotariu, T. Towards developing an efficient sensitive element for trinitrotoluene detection: $\mathrm{TiO}_{2}$ thin films functionalized with molecularly imprinted copolymer films. Appl. Surf. Sci. 2016, 384, 449-458. [CrossRef]

19. Gao, D.M.; Zhang, Z.P.; Wu, M.H.; Xie, C.G.; Guan, G.J.; Wang, D.P. A surface functional monomer-directing strategy for highly dense imprinting of tnt at surface of silica nanoparticles. J. Am. Chem. Soc. 2007, 129, 7859-7866. [CrossRef]

20. Guan, G.J.; Liu, R.Y.; Mei, Q.S.; Zhang, Z.P. Molecularly imprinted shells from polymer and xerogel matrices on polystyrene colloidal spheres. Chemistry 2012, 18, 4692-4698. [CrossRef]

21. Niu, Q.Y.; Gao, K.Z.; Lin, Z.H.; Wu, W.H. Surface molecular-imprinting engineering of novel cellulose nanofibril/conjugated polymer film sensors towards highly selective recognition and responsiveness of nitroaromatic vapors. Chem. Commun. 2013, 49, 9137-9139. [CrossRef] [PubMed]

22. Huynh, T.P.; Sosnowska, M.; Sobczak, J.W.; Kc, C.B.; Nesterov, V.N.; D'Souza, F.; Kutner, W. Simultaneous chronoamperometry and piezoelectric microgravimetry determination of nitroaromatic explosives using molecularly imprinted thiophene polymers. Anal. Chem. 2013, 85, 8361-8368. [CrossRef] [PubMed]

23. Pesavento, M.; D'Agostino, G.; Alberti, G.; Biesuz, R.; Merli, D. Voltammetric platform for detection of 2,4,6-trinitrotoluene based on a molecularly imprinted polymer. Anal. Bioanal. Chem. 2013, 405, 3559-3570. [CrossRef] [PubMed]

24. Alizadeh, T.; Zare, M.; Ganjali, M.R.; Norouzi, P.; Tavana, B. A new molecularly imprinted polymer (MIP)-based electrochemical sensor for monitoring 2,4,6-trinitrotoluene (TNT) in natural waters and soil samples. Biosens. Bioelectron. 2010, 25, 1166-1172. [CrossRef]

25. Alizadeh, T. Preparation of magnetic tnt-imprinted polymer nanoparticles and their accumulation onto magnetic carbon paste electrode for tnt determination. Biosens. Bioelectron. 2014, 61, 532-540. [CrossRef] [PubMed]

26. Shahdost-fard, F.; Roushani, M. Impedimetric detection of trinitrotoluene by using a glassy carbon electrode modified with a gold nanoparticle@fullerene composite and an aptamer-imprinted polydopamine. Microchim. Acta 2017, 184, 3997-4006. [CrossRef]

27. Nie, D.X.; Jiang, D.W.; Zhang, D.; Liang, Y.; Xue, Y.; Zhou, T.S.; Jin, L.T.; Shi, G.Y. Two-dimensional molecular imprinting approach for the electrochemical detection of trinitrotoluene. Sens. Actuators B Chem. 2011, 156, 43-49. [CrossRef]

28. Riskin, M.; Tel-Vered, R.; Bourenko, T.; Granot, E.; Willner, I. Imprinting of molecular recognition sites through electropolymerization of functionalized au nanoparticles: Development of an electrochemical tnt sensor based on pi-donor-acceptor interactions. J. Am. Chem. Soc. 2008, 130, 9726-9733. [CrossRef]

29. Stringer, R.C.; Gangopadhyay, S.; Grant, S.A. Detection of nitroaromatic explosives using a fluorescent-labeled imprinted polymer. Anal. Chem. 2010, 82, 4015-4019. [CrossRef] [PubMed] 
30. Xie, C.G.; Zhang, Z.P.; Wang, D.P.; Guan, G.J.; Gao, D.M.; Liu, J.H. Surface molecular self-assembly strategy for tnt imprinting of polymer nanowire/nanotube arrays. Anal. Chem. 2006, 78, 8339-8346. [CrossRef] [PubMed]

31. Zhu, W.; Tao, S.Y.; Tao, C.A.; Li, W.N.; Lin, C.X.; Li, M.; Wen, Y.Q.; Li, G.T. Hierarchically imprinted porous films for rapid and selective detection of explosives. Langmuir 2011, 27, 8451-8457. [CrossRef]

32. Hassanzadeh, J.; Khataee, A.; Oskoei, Y.M.; Fattahi, H.; Bagheri, N. Selective chemiluminescence method for the determination of trinitrotoluene based on molecularly imprinted polymer-capped zno quantum dots. New J. Chem. 2017, 41, 10659-10667. [CrossRef]

33. Cennamo, N.; D’Agostino, G.; Galatus, R.; Bibbo, L.; Pesavento, M.; Zeni, L. Sensors based on surface plasmon resonance in a plastic optical fiber for the detection of trinitrotoluene. Sens. Actuators B Chem. 2013, 188, 221-226. [CrossRef]

34. Cennamo, N.; Dona, A.; Pallavicini, P.; D’Agostino, G.; Dacarro, G.; Zeni, L.; Pesavento, M. Sensitive detection of 2,4,6-trinitrotoluene by tridimensional monitoring of molecularly imprinted polymer with optical fiber and five-branched gold nanostars. Sens. Actuators B Chem. 2015, 208, 291-298. [CrossRef]

35. Holthoff, E.L.; Stratis-Cullum, D.N.; Hankus, M.E. A nanosensor for tnt detection based on molecularly imprinted polymers and surface enhanced raman scattering. Sensors 2011, 11, 2700-2714. [CrossRef] [PubMed]

36. Yang, L.B.; Ma, L.A.; Chen, G.Y.; Liu, J.H.; Tian, Z.Q. Ultrasensitive sers detection of tnt by imprinting molecular recognition using a new type of stable substrate. Chemistry 2010, 16, 12683-12693. [CrossRef] [PubMed]

37. Lu, W.; Asher, S.A.; Meng, Z.H.; Yan, Z.Q.; Xue, M.; Qiu, L.L.; Yi, D. Visual detection of 2,4,6-trinitrotolune by molecularly imprinted colloidal array photonic crystal. J. Hazard. Mater. 2016, 316, 87-93. [CrossRef] [PubMed]

38. Lu, W.; Dong, X.; Qiu, L.L.; Yan, Z.Q.; Meng, Z.H.; Xue, M.; He, X.; Liu, X.Y. Colorimetric sensor arrays based on pattern recognition for the detection of nitroaromatic molecules. J. Hazard. Mater. 2017, 326, 130-137. [CrossRef]

39. Walker, N.R.; Linman, M.J.; Timmers, M.M.; Dean, S.L.; Burkett, C.M.; Lloyd, J.A.; Keelor, J.D.; Baughman, B.M.; Edmiston, P.L. Selective detection of gas-phase tnt by integrated optical waveguide spectrometry using molecularly imprinted sol-gel sensing films. Anal. Chim. Acta 2007, 593, 82-91. [CrossRef]

40. Edmiston, P.L.; Campbell, D.P.; Gottfried, D.S.; Baughman, J.; Timmers, M.M. Detection of vapor phase trinitrotoluene in the parts-per-trillion range using waveguide interferometry. Sens. Actuators B Chem. 2010, 143, 574-582. [CrossRef]

41. Bunte, G.; Hurttlen, J.; Pontius, H.; Hartlieb, K.; Krause, H. Gas phase detection of explosives such as 2,4,6-trinitrotoluene by molecularly imprinted polymers. Anal. Chim. Acta 2007, 591, 49-56. [CrossRef] [PubMed]

42. Bunte, G.; Heil, M.; Roseling, D.; Hurttlen, J.; Pontius, H.; Krause, H. Trace detection of explosives vapours by molecularly imprinted polymers for security measures. Propellants Explos. Pyrotech. 2009, 34, 245-251. [CrossRef]

43. Trammell, S.A.; Zeinali, M.; Melde, B.J.; Charles, P.T.; Velez, F.L.; Dinderman, M.A.; Kusterbeck, A.; Markowitz, M.A. Nanoporous organosilicas as preconcentration materials for the electrochemical detection of trinitrotoluene. Anal. Chem. 2008, 80,4627-4633. [CrossRef] [PubMed]

44. Lu, W.; Li, H.Y.; Meng, Z.H.; Liang, X.X.; Xue, M.; Wang, Q.H.; Dong, X. Detection of nitrobenzene compounds in surface water by ion mobility spectrometry coupled with molecularly imprinted polymers. J. Hazard. Mater. 2014, 280, 588-594. [CrossRef]

45. Bianchi, F.; Giannetto, M.; Mori, G.; D’Agostino, G.; Careri, M.; Mangia, A. Solid-phase microextraction of 2,4,6-trinitrotoluene using a molecularly imprinted-based fiber. Anal. Bioanal. Chem. 2012, 403, 2411-2418. [CrossRef]

46. Alizadeh, T.; Atashi, F.; Ganjali, M.R. Molecularly imprinted polymer nano-sphere/multi-walled carbon nanotube coated glassy carbon electrode as an ultra-sensitive voltammetric sensor for picomolar level determination of rdx. Talanta 2019, 194, 415-421. [CrossRef] 
47. Wang, J.; Meng, Z.H.; Xue, M.; Qiu, L.L.; Zhang, C.F. Separation of 1,3,5,7-tetranitro-1,3,5,7-tetraazacyclooctane and 1,3,5-trinitro-1,3,5-triazacyclohexane by molecularly imprinted solid-phase extraction. J. Sep. Sci. 2017, 40, 1201-1208. [CrossRef]

48. Mamo, S.K.; Gonzalez-Rodriguez, J. Development of a molecularly imprinted polymer-based sensor for the electrochemical determination of triacetone triperoxide (tatp). Sensors 2014, 14, 23269-23282. [CrossRef]

49. Huynh, T.P.; Wojnarowicz, A.; Kelm, A.; Woznicki, P.; Borowicz, P.; Majka, A.; D’Souza, F.; Kutner, W. Chemosensor for selective determination of 2,4,6-trinitrophenol using a custom designed imprinted polymer recognition unit cross-linked to a fluorophore transducer. ACS Sens. 2016, 1, 636-639. [CrossRef]

50. Wang, J.; Xue, M.; Meng, Z.H.; Xu, Z.B.; Luo, J. Application of molecularly imprinted polymers for the solid-phase extraction of hexanitrohexaazaisowurtzitane (cl-20) from soil samples. Anal. Methods 2016, 8, 4413-4420. [CrossRef]

51. Wang, J.; Meng, Z.H.; Xue, M.; Qiu, L.L.; Dong, X.; Xu, Z.B.; He, X.; Liu, X.; Li, J.S. Simultaneous selective extraction of nitramine explosives using molecularly imprinted polymer hollow spheres from post blast samples. New J. Chem. 2017, 41, 1129-1136. [CrossRef]

52. Nie, D.X.; Han, Z.; Yu, Y.Y.; Shi, G.Y. Composites of multiwalled carbon nanotubes/polyethyleneimine (mwcnts/pei) and molecularly imprinted polymers for dinitrotoluene recognition. Sens. Actuators B Chem. 2016, 224, 584-591. [CrossRef]

53. Dai, J.J.; Dong, X.Q.; de Cortalezzi, M.F. Molecularly imprinted polymers labeled with amino-functionalized carbon dots for fluorescent determination of 2,4-dinitrotoluene. Microchim. Acta 2017, 184, 1369-1377. [CrossRef]

54. Apodaca, D.C.; Pernites, R.B.; Del Mundo, F.R.; Advincula, R.C. Detection of 2,4-dinitrotoluene (dnt) as a model system for nitroaromatic compounds via molecularly imprinted short-alkyl-chain sams. Langmuir 2011, 27, 6768-6779. [CrossRef] [PubMed]

55. Lordel, S.; Chapuis-Hugon, F.; Eudes, V.; Pichon, V. Development of imprinted materials for the selective extraction of nitroaromatic explosives. J. Chromatogr. A 2010, 1217, 6674-6680. [CrossRef]

56. Lordel, S.; Chapuis-Hugon, F.; Eudes, V.; Pichon, V. Selective extraction of nitroaromatic explosives by using molecularly imprinted silica sorbents. Anal. Bioanal. Chem. 2011, 399, 449-458. [CrossRef] [PubMed]

57. Lordel-Madeleine, S.; Eudes, V.; Pichon, V. Identification of the nitroaromatic explosives in post-blast samples by online solid phase extraction using molecularly imprinted silica sorbent coupled with reversed-phase chromatography. Anal. Bioanal. Chem. 2013, 405, 5237-5247. [CrossRef]

58. Riskin, M.; Tel-Vered, R.; Willner, I. Imprinted au-nanoparticle composites for the ultrasensitive surface plasmon resonance detection of hexahydro-1,3,5-trinitro-1,3,5-triazine (rdx). Adv. Mater. 2010, 22, 1387-1391. [CrossRef]

59. Riskin, M.; Ben-Amram, Y.; Tel-Vered, R.; Chegel, V.; Almog, J.; Willner, I. Molecularly imprinted au nanoparticles composites on au surfaces for the surface plasmon resonance detection of pentaerythritol tetranitrate, nitroglycerin, and ethylene glycol dinitrate. Anal. Chem. 2011, 83, 3082-3088. [CrossRef]

60. Shi, L.; Hou, A.G.; Chen, L.Y.; Wang, Z.F. Electrochemical sensor prepared from molecularly imprinted polymer for recognition of tnt. Polym. Compos. 2015, 36, 1280-1285. [CrossRef]

61. Xu, S.F.; Lu, H.Z.; Li, J.H.; Song, X.L.; Wang, A.X.; Chen, L.X.; Han, S.B. Dummy molecularly imprinted polymers-capped cdte quantum dots for the fluorescent sensing of 2,4,6-trinitrotoluene. ACS Appl. Mater. Interface 2013, 5, 8146-8154. [CrossRef] [PubMed]

62. Xu, S.F.; Lu, H.Z. Ratiometric fluorescence and mesoporous structure dual signal amplification for sensitive and selective detection of tnt based on mip@qd fluorescence sensors. Chem. Commun. 2015, 51, 3200-3203. [CrossRef]

63. Xu, S.F.; Lu, H.Z. Mesoporous structured mips@cds fluorescence sensor for highly sensitive detection of tnt. Biosens. Bioelectron. 2016, 85, 950-956. [CrossRef] [PubMed]

64. Riskin, M.; Tel-Vered, R.; Lioubashevski, O.; Willner, I. Ultrasensitive surface plasmon resonance detection of trinitrotoluene by a bis-aniline-cross-linked au nanoparticles composite. J. Am. Chem. Soc. 2009, 131, 7368-7378. [CrossRef]

65. Ebrahimzadeh, H.; Abedi, H.; Yamini, Y.; Adlnasab, L. Molecular-imprinted polymer extraction combined with dispersive liquid-liquid micro-extractionfor ultra-preconcentration of mononitrotoluene. J. Sep. Sci. 2010, 33, 3759-3766. [CrossRef] [PubMed] 
66. Fatah, A.A.; Arcilesi, R.D.; McClintock, J.A.; Lattin, C.H.; Helinski, M.; Hutchings, M. Guide for the Selection of Explosives Detection and Blast Mitigation Equipment for Emergency First Responders; Department of Homeland Security: Washington, WA, USA, 2008.

67. Borsdorf,H.; Mayer, T.; Zarejousheghani, M.; Eiceman, G.A. Recent developments in ion mobility spectrometry. Appl. Spectrosc. Rev. 2011, 46, 472-521. [CrossRef]

68. Crockett, A.B.; Craig, H.D.; Jenkins, T.F. Field Sampling and Selecting On-Site Analytical Methods for Explosives in Water; United States Environmental Protection Agency: Washington, WA, USA, 1999; p. 47.

69. Roh, S.; Chung, T.; Lee, B. Overview of the characteristics of micro- and nano-structured surface plasmon resonance sensors. Sensors 2011, 11, 1565-1588. [CrossRef] [PubMed]

70. Zarejousheghani, M.; Walte, A.; Borsdorf, H. Sprayed liquid-gas extraction of semi-volatile organophosphate malathion from air and contaminated surfaces. Anal. Methods 2018, 10, 2503-2511. [CrossRef]

71. Reinecke, T.; Walter, J.G.; Kobelt, T.; Ahrens, A.; Scheper, T.; Zimmermann, S. Design and evaluation of split-ring resonators for aptamer-based biosensors. J. Sens. Sens. Syst. 2018, 101-111. [CrossRef]

72. Reinecke, T.; Walter, J.G.; Kobelt, T.; Ahrens, A.; Scheper, T.; Zimmermann, S. Biosensor based on a split-ring resonator. In Proceedings of the AMA Conferences 2017, Nürnberg, Germany, 30 May-1 June 2017; pp. 78-83.

(C) 2019 by the authors. Licensee MDPI, Basel, Switzerland. This article is an open access article distributed under the terms and conditions of the Creative Commons Attribution (CC BY) license (http://creativecommons.org/licenses/by/4.0/). 